\title{
Physical Simulation of Colayer Water Flooding in Low Permeability Carbonate Reservoir in Middle East
}

\author{
Xingwang Shi, ${ }^{1,2}$ Zhengming Yang, ${ }^{2,3}$ Yapu Zhang, ${ }^{2,3}$ Guangya Zhu, ${ }^{3}$ and Qianhua Xiao ${ }^{4}$ \\ ${ }^{1}$ University of Chinese Academy of Sciences, Beijing 100049, China \\ ${ }^{2}$ Department of Porous Flow \& Fluid Mechanics, Chinese Academy of Sciences, Langfang 065007, China \\ ${ }^{3}$ PetroChina Research Institute of Petroleum Exploration \& Development, Beijing 100083, China \\ ${ }^{4}$ Chongqing University of Science \& Technology, Chongqing 401331, China
}

Correspondence should be addressed to Xingwang Shi; shixingwang15@mails.ucas.ac.cn

Received 7 April 2017; Revised 13 August 2017; Accepted 19 September 2017; Published 1 November 2017

Academic Editor: Runcang Sun

Copyright (C) 2017 Xingwang Shi et al. This is an open access article distributed under the Creative Commons Attribution License, which permits unrestricted use, distribution, and reproduction in any medium, provided the original work is properly cited.

\begin{abstract}
To study the flow mechanism under different displacement modes of low permeability carbonate reservoir in the Middle East and to improve the utilization of various types of reservoirs, the physical simulation experiments of water flooding by different displacement methods were carried out. Selecting two types of rock samples with different permeability levels, two-layer coinjection and separated production experiments by samples I and III and conventional water flooding experiments by samples II and IV were carried out. In addition, by using low magnetic field nuclear magnetic resonance, the development effect of microscopic pore structure under the different injection-production models was analyzed. Results show that, compared with the coinjection, the recovery rate of sample I was higher than II, $19.30 \%$; sample III was lower than IV, $23.22 \%$; and the comprehensive recovery degree reduced by $3.92 \%$. NMR data also show that the crude oil is mainly distributed in the large pore throat; after water flooding, the displacement is also within the large pore throat, whereas the small pore throat is mainly obtained by the effect of infiltration absorption. The above studies provide a laboratory basis and foundation for the further development of low permeability carbonate reservoir in different Middle East strata.
\end{abstract}

\section{Introduction}

In recent years, the rational development of carbonate reservoirs has become a hot spot in the domestic and international oil industry. Most of the reservoirs that China was involved in their acquisition and development in the Middle East belong to the low permeability carbonate reservoirs. But the vertical heterogeneity of these reservoirs is strong, the contradiction between layers is prominent, the water content of some layers rises rapidly, and the degree of recovery is lower, which greatly influenced Chinese government for the oilfield development. Therefore, in order to recover the cost as soon as possible during the contract period and to improve the recovery degree and maximize the enterprise benefits, there are urgent needs for studying diverse development methods to improve the usage of various types of reservoirs.

Numerous scholars conducted a series of laboratory experiments on the heterogeneity characteristics of oilfields in different regions and suggested that ameliorating the water injection structure could improve the water absorption status and recovery degree through reasonable subdivision [1-4]. These research results are crucial for the efficient development of oil and gas fields, but mainly for Chinese domestic oil fields; less research on low permeability carbonate reservoirs in the Middle East rarely has a reference value. Therefore, based on the previous studies [5-8], we carried out colayer water flooding indoor simulation experiments and studied the microdistribution situation of residual oil and recovery degree of different pore range by means of low nuclear magnetic resonance (NMR) technique $[9,10]$. We performed two different injection-production modes water flooding oil experiment under three states, which guide us to have a more comprehensive understanding on the effect of different interval microscopic pore structure. The results provide some efficient technical policies for the development of Middle East reservoir. In addition, it has certain reference value for the development of colayer water flooding in other low permeability carbonate reservoir. 
TABLE 1: Physical parameters of core samples.

\begin{tabular}{lcccccc}
\hline Sample number & Length $(\mathrm{cm})$ & Diameter $(\mathrm{cm})$ & Permeability $\left(10^{-3} \mu \mathrm{m}^{2}\right)$ & Porosity $(\%)$ & $\begin{array}{c}\text { Irreducible water } \\
\text { saturation }(\%)\end{array}$ & $\begin{array}{c}\text { Injection-production } \\
\text { patterns }\end{array}$ \\
\hline (I) & 6.263 & 3.786 & 6.061 & 23.05 & 42.99 & Co-in \\
(II) & 6.239 & 3.797 & 7.659 & 24.48 & 25.89 & Si-in \\
(III) & 6.364 & 3.787 & 15.491 & 20.53 & 27.87 & Co-in \\
(IV) & 6.502 & 3.551 & 19.447 & 14.52 & 26.99 & Si-in \\
\hline
\end{tabular}

Note. Co-in represents 2-layer coinjection separate production; $\mathrm{Si}$-in represents single layer injection and production.

NMR technique as a new rock analysis technology developed rapidly in recent years in the petroleum industry. It can reflect the pore size distribution and the fluid volume in different pores, which can quantitatively calculate the displacement efficiency and residual oil in different pore size during water flooding oil. Therefore, NMR technique is a potent supplement of routine laboratory water flooding technology [11]. NMR could detect the signal of hydrogen nucleus ${ }^{1} H$, while, having fluid (oil or water) in the cores, NMR has different reflection in $T_{2}$ spectra. The property and amount of internal fluid could influence the shape of the $T_{2}$ spectra, which reflect the size of pore and throat. NMR relaxation time reflects core's pore size. According to the study [12], the corresponding pores are as follows: clay micropores when the relaxation time is less than $10 \mathrm{~ms}$, large pores when relaxation time $T_{2}$ is greater than $100 \mathrm{~ms}$, and medium pore when relaxation time $T_{2}$ is $10 \mathrm{~ms}-100 \mathrm{~ms}$. According to the property of recognizing hydrogen nucleus ${ }^{1} \mathrm{H}$ of NMR technique, chlorofluorocarbon synthetic oil (no hydrogen nucleus ${ }^{1} H$ ) was adopted to conduct physical simulation experiment, so that the signal measured by the NMR relaxation time spectrum was the distribution of the water phase in the rock sample.

\section{Experimental Design}

According to the logging interpretation and core statistics, the average permeability of the Middle East $\mathrm{M}$ group is 18 $65 \times 10^{-3} \mu \mathrm{m}^{2}$ and the porosity is $14 \sim 22 \%$. In vertical, the stratum is divided into three segments and 15 small layers, which indicate strong heterogeneous. Therefore, we used two sets of rock samples with different permeability difference to carry out the water flooding experiment of coinjection and separate production and used the single layer injection and production as the contrast experiment. Combining the nuclear magnetic resonance technique, we also studied the distribution of microscopic residual oil and recovery degree. The experiment adopts 2 layer samples connecting in parallel, simultaneously injecting, and, respectively, measuring way to simulate the mine field reservoir 2-layer water flooding process. The basic parameters of rock samples are shown in Table 1.

The experiment was carried out at room temperature. The experiment oil was chlorofluorocarbon synthetic oil. The density of synthetic oil is $1.8 \mathrm{~g} / \mathrm{cm}^{3}$ at $20^{\circ} \mathrm{C}$, and the viscosity is $3.2 \mathrm{mPa} \cdot \mathrm{s}$. The experimental water is the simulated formation water based on the results of water quality test configuration, the mineralization degree is $200000 \mathrm{mg} / \mathrm{L}$ at $20^{\circ} \mathrm{C}$, and the viscosity is $1.15 \mathrm{mPa} \cdot \mathrm{s}$. The experiment adopts constant pressure flooding way, the average single layer injection pressure is $0.2 \mathrm{MPa}$, and the outlet pressure is normal pressure.

Figure 1 is the schematic diagram of the experiment process of the 2-layer coinjection and separate production. The QUAZIX type displacement pump simulates the formation water into the rock sample, and the confining pressure is applied to the core by the ring pressure pump. The experimental pressure is measured by the sensor, oil-water mixture flowing out from the exit end of the rock sample is, respectively, measured after being separated by the separator; that is, measurement accuracy is $0.01 \mathrm{~cm}^{3}$.

Specific experimental procedures are as follows: (1) simulate saturated water condition; saturate rock sample with simulated formation water to $10 \mathrm{PV}$ after the rock sample vacuums, and proceed with saturated water condition $T_{2}$ spectrum test; (2) simulate saturated oil condition. Displacing rock sample with chlorofluorocarbon synthetic oil to $10 \mathrm{PV}$ after the rock sample is loaded to the core holder in parallel, and proceed with saturated oil condition $T_{2}$ spectrum test; (3) simulate oil condition. Injecting the rock sample with simulated formation water at constant pressure, record displacement speed, displacement confining pressure, and the amount of displacement oil and water at different times until there is no oil, and proceed with residual oil condition $T_{2}$ spectrum test.

\section{Results Analysis}

Figure 2 and Table 2 show the results of water flooding in different injection-production patterns with different permeability levels. It can be seen that, under the same injectionproduction patterns, the anhydrous recovery degree, residual oil saturation, and final recovery degree of different permeability levels are significantly different. When the low permeability layer I and high permeability layer III are simultaneously injected by constant pressure, most of injected water flooded into high permeability layer, causing the water in high permeability layer to break through. The water breakthrough time is $460 \mathrm{~s}$, less than the low permeability $2875 \mathrm{~s}$, and the anhydrous recovery degree is $7.11 \%$, less than the low permeability $23.10 \%$. Due to the fact that the high permeability layer likely forms water phase dominant flow channel and the injected water has lower degree of impact to other interval after water breakthrough, while continuously injecting water with the same pressure, this will result in the final recovery degree being lower, only $34.78 \%$. But the low permeability layer still maintains the condition of oil and water infiltration under the lower displacement speed, which could unceasingly displace the oil phase of pores forward, 


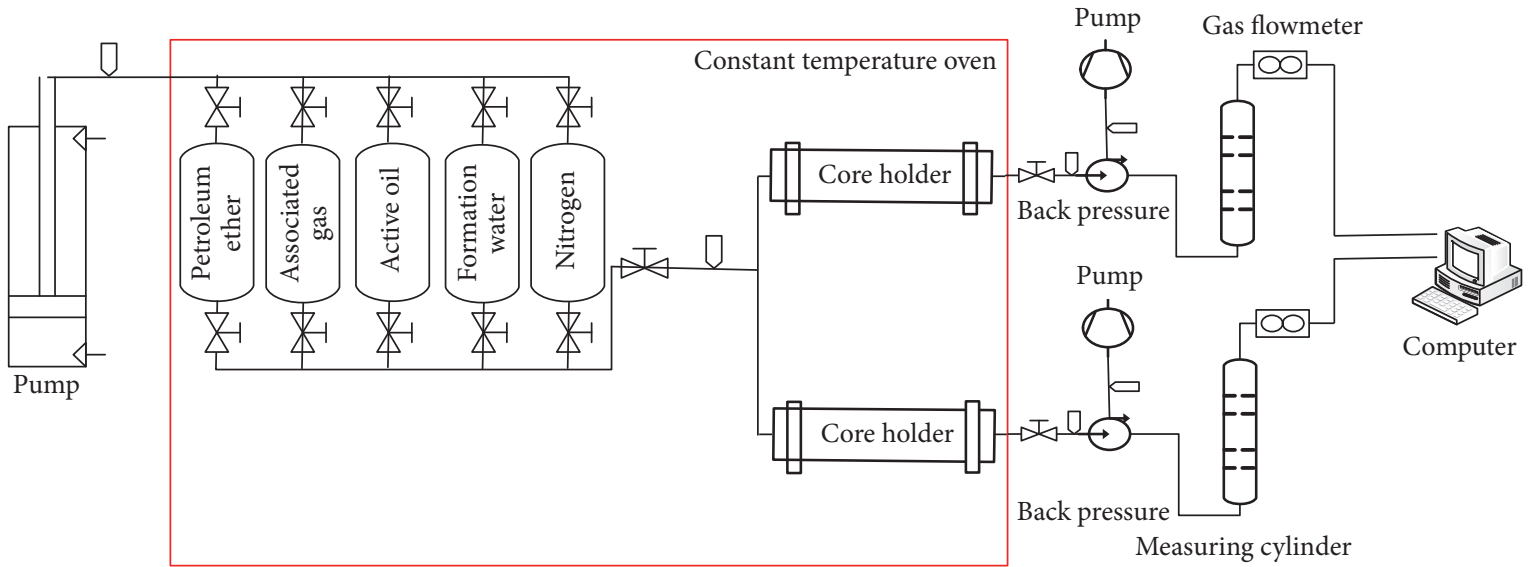

\footnotetext{
$\square$ Pressure sensor

Zi value
}

FIGURE 1: Experiment flow chart of coinjection and separate production water flooding.

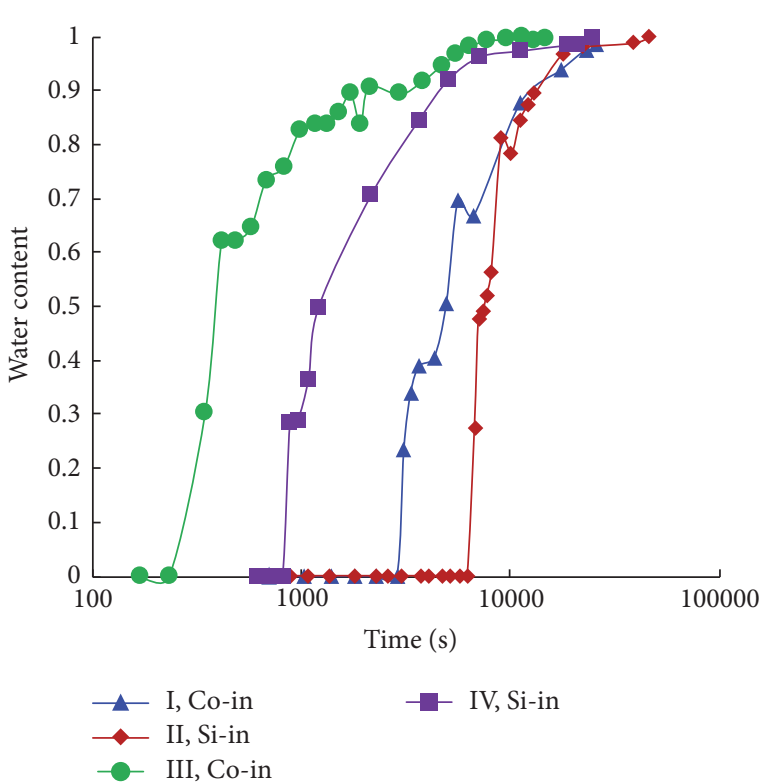

(a) Water content variation with time curve

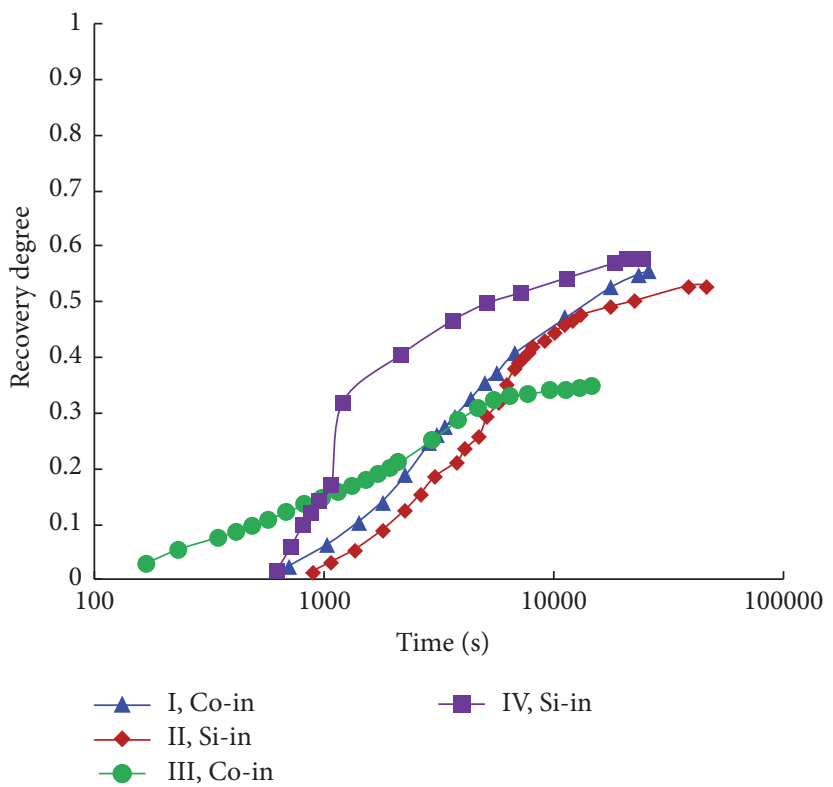

(b) Recovery degree variation with time curve

FIGURE 2: Experiment results of water content and recovery degree curve.

TABLE 2: Experiment results of different injection-production patterns of samples.

\begin{tabular}{lcccccc}
\hline Sample number & $\begin{array}{c}\text { Permeability } \\
\left(10^{-3} \mu \mathrm{m}^{2}\right)\end{array}$ & Porosity (\%) & $\begin{array}{c}\text { Injection-production } \\
\text { patterns }\end{array}$ & $\begin{array}{c}\text { Anhydrous recovery } \\
\text { degree (\%) }\end{array}$ & $\begin{array}{c}\text { Residual oil } \\
\text { saturation (\%) }\end{array}$ & $\begin{array}{c}\text { Final recovery } \\
\text { degree }(\%)\end{array}$ \\
\hline (I) & 6.061 & 23.05 & Co-in & 23.10 & 25.27 & 55.68 \\
(II) & 7.659 & 24.48 & Si-in & 20.00 & 43.78 & 36.38 \\
(III) & 15.491 & 20.53 & Co-in & 7.11 & 37.04 & 31.76 \\
(IV) & 19.447 & 14.52 & Si-in & 12.39 & 58.00 \\
\hline
\end{tabular}

Note. Co-in represents 2-layer coinjection separate production; $\mathrm{Si}$-in represents single layer injection and production. 


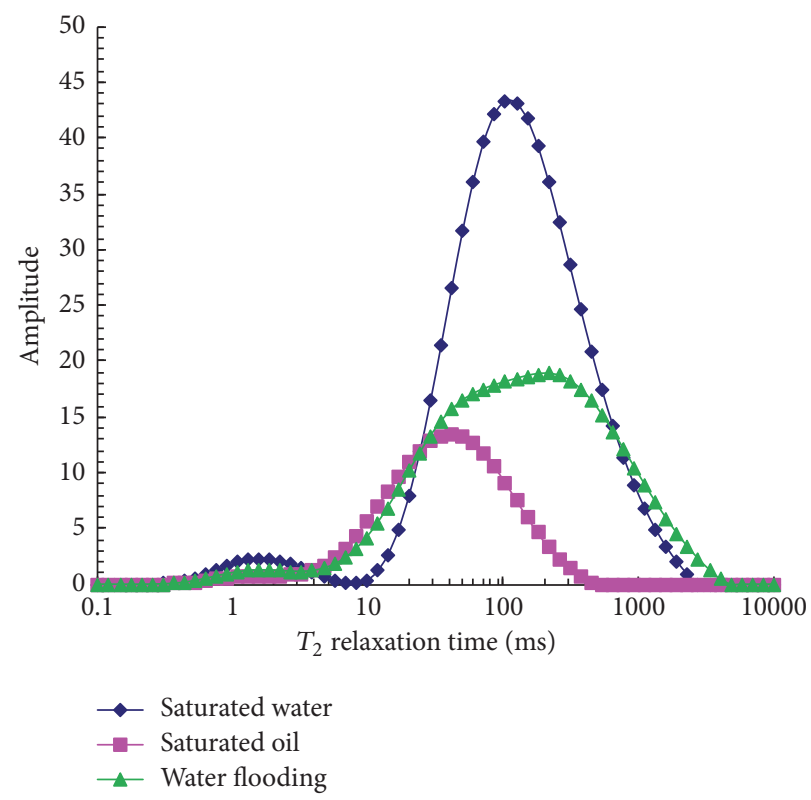

(a) Rock sample I coinjection separate production

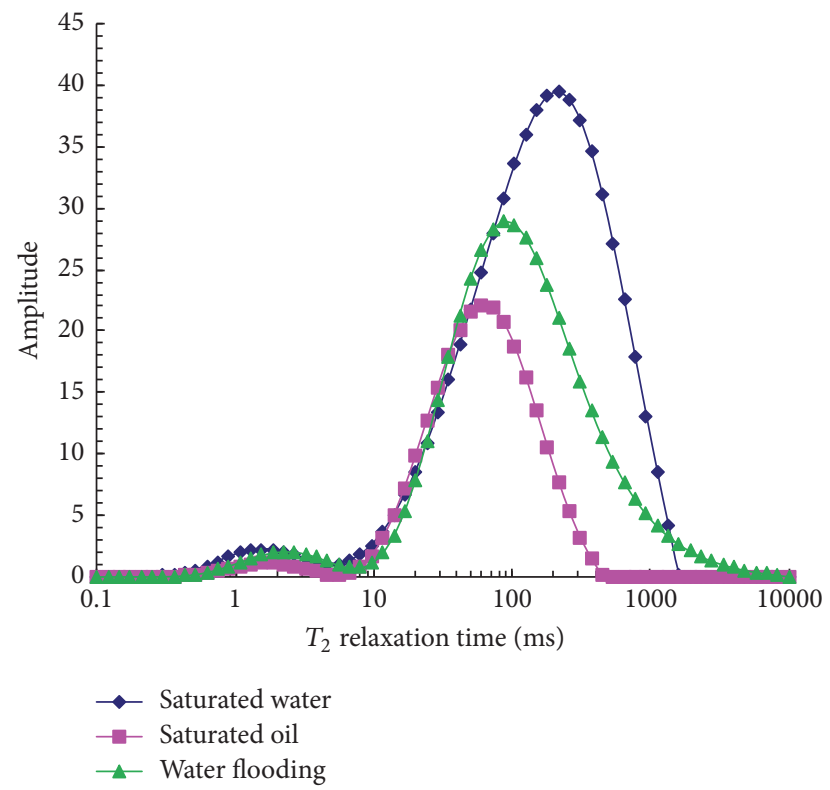

(c) Rock sample III coinjection separate production

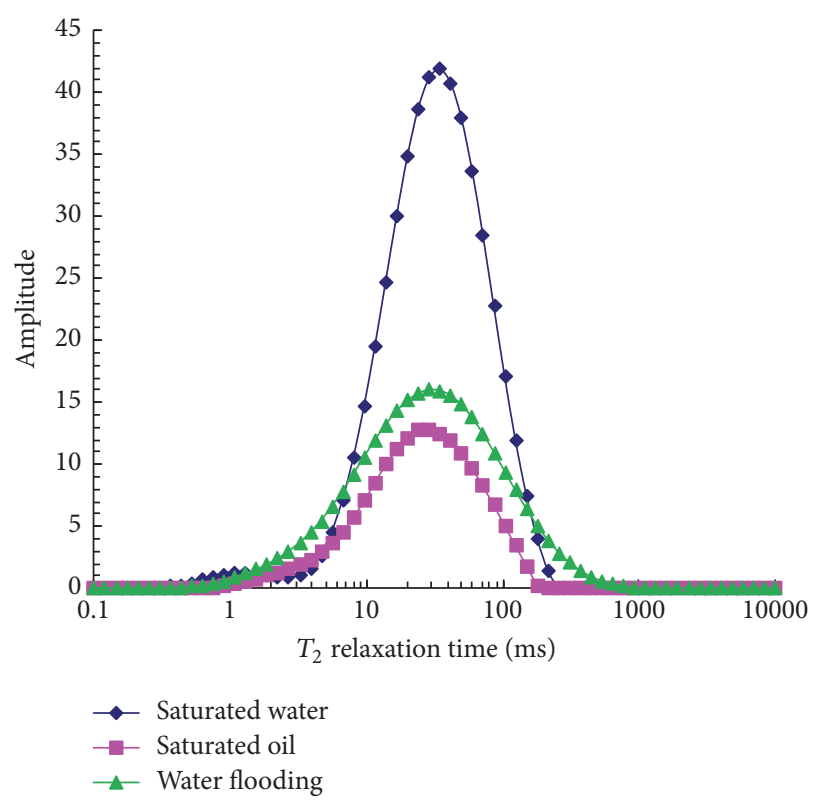

(b) Rock sample II single layer injection and production

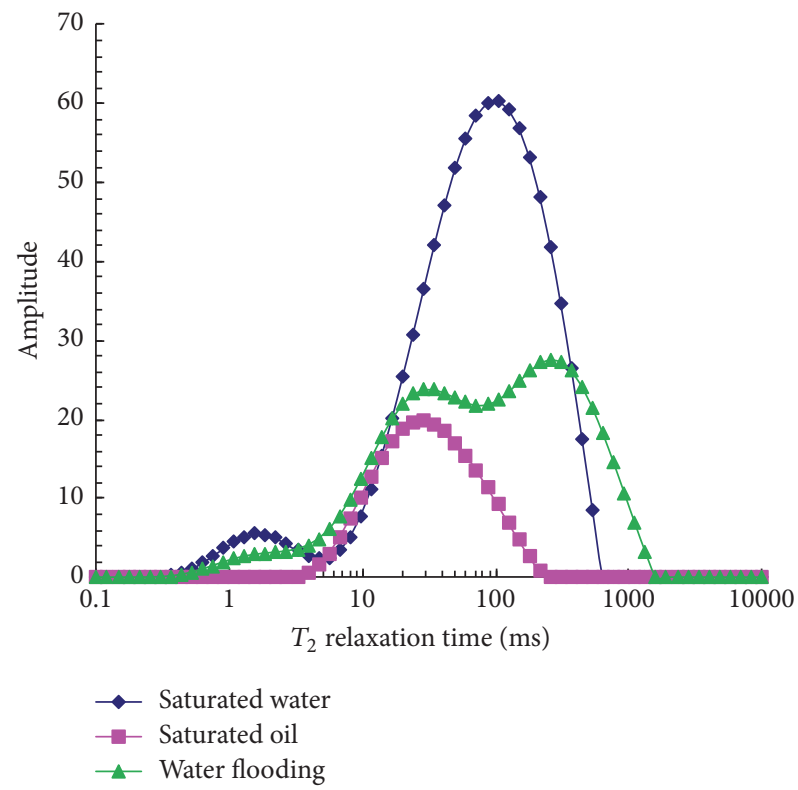

(d) Rock sample IV single layer injection and production

FIGURE 3: NMR $T_{2}$ spectra comparison of different injection-production modes.

resulting in the final recovery degree being high, reaching $55.68 \%$. When displacing the low permeability layer II and the high permeability layer IV with the constant pressure, the water breakthrough time is $7800 \mathrm{~s}$ and $950 \mathrm{~s}$ respectively, and the anhydrous recovery degree is $20.00 \%$ and $12.39 \%$, respectively. It can be seen that the lower permeability has higher anhydrous recovery degree. But the final recovery degree of high permeability is $58.00 \%$, higher than the low permeability, $36.38 \%$.

For the same permeability level of rock samples, different injection-production patterns on its recovery degree exert tremendous influence. Rock sample I that adopt coinjection and separate production pattern enhances anhydrous recovery degree $3.10 \%$ compared to rock sample II that adopts single layer injection and production pattern, enhances the final recovery degree $19.30 \%$, and reduces the residual oil saturation $18.51 \%$. Rock sample IV that adopts single layer injection and production pattern enhances anhydrous recovery degree $5.28 \%$ compared to rock sample III that adopts coinjection and separates production pattern, enhances the final recovery degree $23.22 \%$, reduces the residual oil saturation $15.28 \%$, and reduces the comprehensive recovery degree by $3.92 \%$.

Figure 3 shows the process of water flooding NMR $T_{2}$ spectrum of two group different permeability level rock 
samples. It can be seen that the different permeability samples with the same injection-production patterns have diverse responses; the same permeability samples with different injection-production patterns also have diverse responses. The $T_{2}$ spectra of 4 rock samples are dominated by bimodal form, which indicate that there are two or more types of pore structures in the rock samples. For the same injectionproduction patterns (I and II, III, and IV), as the permeability increases, the NMR $T_{2}$ spectrum moves to the right gradually, indicating that the movable fluid is aggrandized gradually.

From the saturated oil curve, the irreducible water is mainly distributed in the small pores, few in the large pores, which is because, during the formation process of bound water, the oil phase preferentially flows along the macropore, displacing the water in the large pores and leaving the water in the small pores to form irreducible water. From the water flooding curve and the saturated oil curve, the main displacement oil is distributed primarily in the large pores, few in the small pores, which is because, in the process of displacement, water phase likely flows along the large pores with small flow resistance, hence driving out the most of oil phase. From the saturated water curve and the water flooding curve, the residual oil is primarily distributed in the large pores, rarely in the small pores, which is because oil phase in the small pores is seldom and coupled with the effect of infiltration absorption, resulting in residual oil saturation in small pores being scarce, whereas residual oil likely forms in the rock surface and irregular formation of large pores.

\section{Conclusions}

(1) In the same injection-production modes, the higher permeability rock samples break through the water earlier, and the period of anhydrous recovery degree is relatively short. While breaking through the water, water content rise rapidly. The lower permeability rock samples break through the water relatively late, and the anhydrous recovery degree is larger than the higher permeability rock samples. In the same permeability level, the mode of coinjection separate production breaks through water earlier than the mode of single layer injection and production.

(2) The higher permeability rock samples have lower recovery degree while adopting coinjection and separate production modes than adopting single layer injection and production modes. In contrast, the lower permeability rock samples have higher recovery degree while adopting coinjection and separate production modes than adopting single layer injection and production modes. Therefore, for the different permeability levels, rock samples should take different injection-production modes, and the specific combination boundaries need further study.

(3) The irreducible water is mainly distributed in the small pores. During the displacement process, the oil phase was driven primary on the large pores. Moreover, the residual oil primary concentrated in the large pores due to the small pores being scarcely saturated oil phase. The large pores still have enormous development potential.

\section{Conflicts of Interest}

The authors declare that they have no conflicts of interest.

\section{Acknowledgments}

This research was supported by the National Oil and Gas Major Project of China (Grant 2017ZX05013-001, Physical Simulation Method and Seepage Mechanism for Ultralow Permeability Reservoirs) and the National Natural Science Foundation of China (Grant 51604053, Micro- and Nanoscale Porous Flow Mechanism and Mathematical Model for Tight Oil Reservoirs). Thanks are due to the authors' tutors, Dr. Zhengming Yang and Yapu Zhang, and other professors, Dr. Guangya Zhu and Qianhua Xiao, for their professional guidance.

\section{References}

[1] G. Czyzewski, H. Hornford, P. Maclean, and M. Carlson, "The east swan hills unit waterflood optimization study: a multidisciplinary approach," Journal of Canadian Petroleum Technology, vol. 31, no. 05, 2013.

[2] C. Dabbouk, A. Liaqat, G. Williams et al., "Waterflood in vuggy layer of a middle east reservoir," Displacement Physics Understood, 2002.

[3] Y. Zhijun, L. Guoyong, Z. Xiang et al., "Heterogeneity of nonmarine reservoirs and its influences on recovery factor: take Gaoshangpu and Yonganzhen oil reservoirs in Jidong and shengli oilfields as examples," Oil \& Gas Geology, vol. 27, no. 1, pp. 106-110, 2006.

[4] A. H. Alizadeh, M. Khishvand, M. A. Ioannidis, and M. Piri, "Multi-scale experimental study of carbonated water injection: An effective process for mobilization and recovery of trapped oil," Fuel, vol. 132, pp. 219-235, 2014.

[5] J. G. Richardson and F. M. Perkins Jr., "A laboratory investigation of the effect of the rate on recovery of oil by waterflooding," Journal of Petroleum Technology, vol. 210, no. 4, pp. 114-121, 1957.

[6] Y. Chunsheng, L. Min, Q. Guoan et al., "Vertically heterogeneous reservoir water flooding oil test," Journal of Southwest Petroleum University (Science \& Technology Edition), vol. 31, no. 1, pp. 84-86, 2009.

[7] M. R. Alhamdan, Y. Cinar, V. S. Suicmez, and B. Dindoruk, "Experimental and numerical study of compositional twophase displacements in layered porous media," Journal of Petroleum Science and Engineering, vol. 98-99, pp. 107-121, 2012.

[8] Z. Li, H. Chen, C. Yu, L. Du, Y. Qiao, and W. Liu, "Hydrodynamic geological effect during the waterflooding of seriously heterogeneous reservoirs," Petroleum Exploration and Development, vol. 40, no. 2, pp. 224-229, 2013.

[9] A. T. Watson and C. T. P. Chang, "Characterizing porous media with NMR methods," Progress in Nuclear Magnetic Resonance Spectroscopy, vol. 31, no. 4, pp. 343-386, 1997.

[10] Z. Xu and S. Guo, "Application of NMR and X-CT technology in the pore structure study of shale gas reservoirs," Advances in Earth Science, vol. 29, no. 5, pp. 624-631, 2014. 
[11] H. E. Mason, M. M. Smith, Y. Hao, and S. A. Carroll, "Calibration of NMR well logs from carbonate reservoirs with laboratory NMR measurements and $\mu \mathrm{XRCT}$,' in Proceedings of the 12th International Conference on Greenhouse Gas Control Technologies, GHGT 2014, pp. 3089-3096, October 2014.

[12] T. Sun, W. Yan, H. Wang, N. Golsanami, and L. Zhang, "Developing a new NMR-based permeability model for fractured carbonate gas reservoirs," Journal of Natural Gas Science and Engineering, vol. 35, pp. 906-919, 2016. 


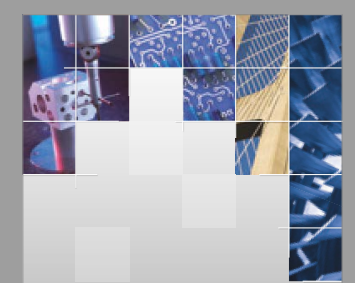

\section{Enfincering}
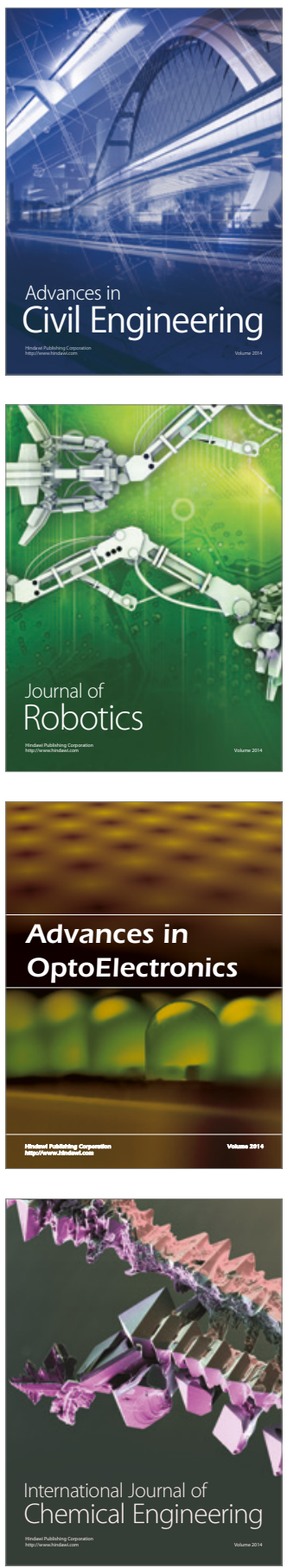

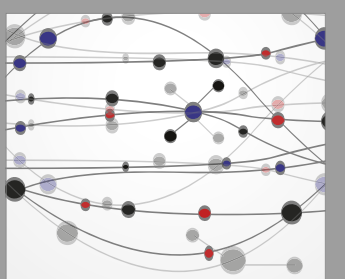

The Scientific World Journal

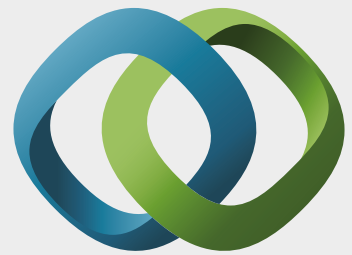

\section{Hindawi}

Submit your manuscripts at

https://www.hindawi.com
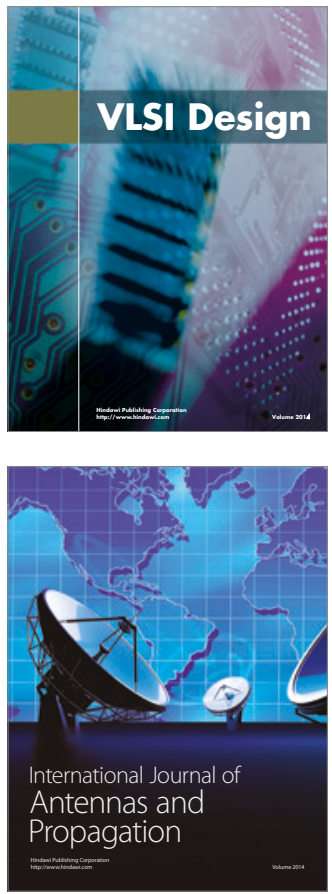

\section{Rotating}

Machinery
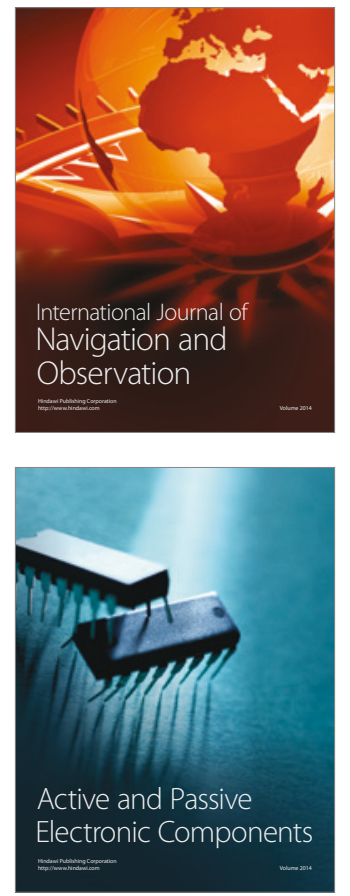
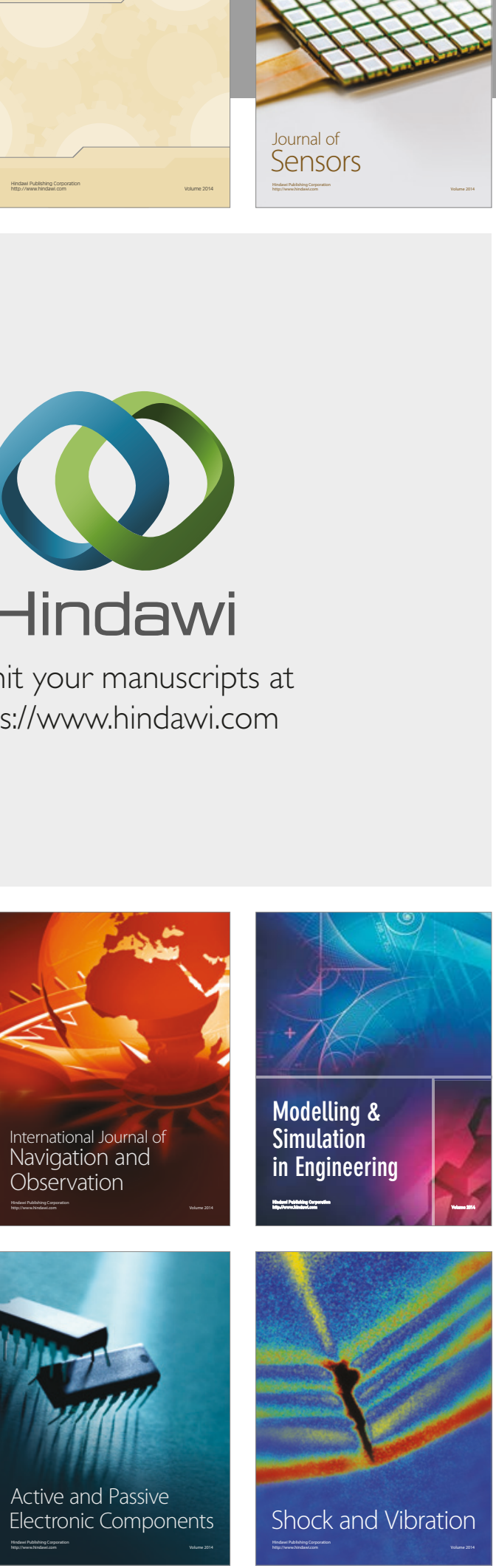
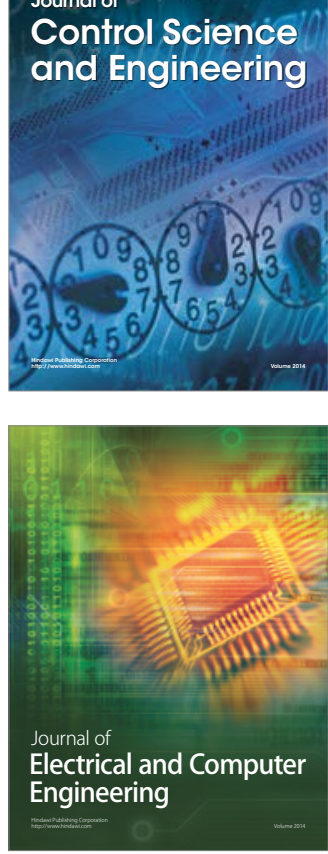

Distributed

Journal of

Control Science

and Engineering
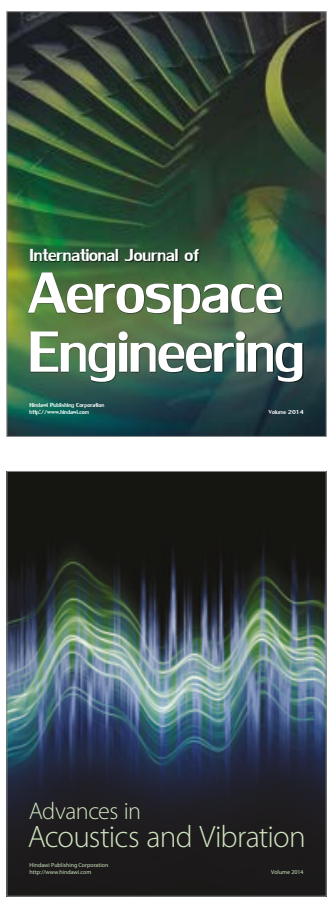

Sensor Networks 